\title{
A sedução da Psicanálise nas páginas das Revistas Femininas Cláudia e Nova de 1970-1990
}

\author{
The seduction of Psychoanalysis in the pages of the Cláudia and Nova \\ Feminine Magazines of 1970-1990
}

Dulcina Tereza Bonati Borges ${ }^{1}$

\begin{abstract}
RESUMO
O presente trabalho visa captar os processos psicológicos subjetivos do movimento de modernização, a partir de uma pesquisa em artigos recolhidos nas Revistas Cláudia e Nova, entre as décadas de 1970-1990, tendo em vista as transformações ocorridas quanto aos valores ético-morais, nessa fase de grandes mudanças sociais. Trata-se de perceber como os discursos das Psicologias e da Psicanálise entram no campo constituído pela mídia, especificamente direcionados para orientar o comportamento feminino, erigindo-se como guia norteador na resolução dos conflitos pessoais e sexuais e da crise da identidade feminina.
\end{abstract}

PALAVRAS-CHAVE: Revistas Femininas. Modernização. Subjetivação.

\begin{abstract}
The presente work aims at capturing the subjective psychological processes of the modernization movement, based on a research on articles collected in the Cláudia and Nova Magazines between the 1970s and 1990s, in view of the transformations that have occurred regarding ethical and moral values social change. It is a question of perceiving how the discourses of Psychology and Psychoanalysis enter into the field constituted by the media, specifically directed to orient the female behavior, erecting itself as guiding guide in the resolution of the personal and sexual conflicts and the crisis of the feminine identity.
\end{abstract}

KEYWORDS: Women's Magazines. Modernization. Subjectivation.

Neste trabalho apresento alguns dos tópicos desenvolvidos na pesquisa da minha Dissertação de Mestrado² realizada em revistas femininas, Cláudia

\footnotetext{
${ }_{1}^{1}$ Doutora em História Cultural pela Universidade Federal de Uberlândia, 2011. Pesquisadora do Núcleo de Estudos de Gênero - NEGUEM/UFU. E-mail: dulcinabb@uol.com.br.

${ }^{2}$ A Cultura Psi das Revistas Femininas: Gênero, Subjetividade e Psicologização (1979-90), defendida sob a orientação da Profa. Dra. Luzia Margareth Rago, na UNICAMP, em maio de 1998.
} 
e Nova, da editora Abril, de 1970-1990, tendo em vista mudanças significativas na representação do feminino e do masculino em nossa sociedade, associadas a novas práticas discursivas trazidas em grande parte pelos movimentos sociais urbanos do período, em especial, o discurso psicológico.

O objetivo central é mostrar como se constituiu uma rede de saber e poder sobre a nova feminilidade, exatamente no discurso da mídia, lugar por excelência de produção e circulação de saberes acerca das subjetividades. $\mathrm{O}$ recorte temporal 1970-1990 se justifica no que tange ao significado deste período histórico. A literatura consultada revela a erupção, a partir da década de 1970, de diversos movimentos sociais urbanos que, inscritos num contexto redemocratização e distensão política, representam um sério questionamento acerca das identidades e da sexualidade, promovendo uma intensa produção e revisão das subjetividades em diversos níveis ${ }^{3}$. Pode-se dizer que um dos vetores de liderança e orientação dos discursos e das práticas foi o fortalecido movimento feminista.

A industrialização e a modernização aceleradas promovidas pela ditadura militar, a partir dos anos 1970, desestabilizou os vínculos tradicionais estabelecidos entre indivíduos e grupos. A família nuclear sofreu uma profunda transformação, à medida em que as mulheres entraram massivamente no mercado de trabalho. Houve a expansão das classes médias urbanas no Brasil e, até o final da década de 1970, embora com alguns refluxos, a economia - sobretudo a industrial - continuou crescendo, particularmente com as grandes empresas, multinacional e estatal, concentrando-se ao mesmo tempo a renda e o capital.

Do ponto de vista estrutural tratou-se, segundo Pastore (PASTORE, José, 1987), “de um processo de mobilidade acompanhada de desigualdade, cujos determinantes mais importantes foram a expansão do emprego e a

\footnotetext{
${ }^{3}$ MACRAE, Edward. A construção da igualdade: identidade sexual e política no Brasil da abertura. Campinas: UNICAMP, 1990; SKIDMORE, Thomas. Brasil. de Castelo a Tancredo. Trad. de Mário Salviano Silva. Rio de Janeiro: Paz e Terra, 1988; ALVAREZ, SONIA. Politizando as relações de gênero e engendrando a democracia. In: Democratizando o Brasil. ALFRED STEPAN (Org.). Trad. de Ana Luiza Pinheiro. Rio de Janeiro: Paz e Terra, 1988.
} 
diferenciação das ocupações no mercado de trabalho, seguida da escolarização". Ao mesmo tempo, as atividades nas áreas de saúde, educação, nas empresas comerciais, artísticas, financeiras e culturais aumentaram o mercado de trabalho para as mulheres de classe média. As ocupações administrativas triplicaram e as técnicas e científicas mais do que duplicaram, oferecendo oportunidades para pessoas de diferentes origens sociais, mas que vieram conformar-se como parte de uma nova classe média, portadora de valores modernos e individualistas (CANO, Wilson, 1986).

Além da expansão do setor privado, o setor público também passou a oferecer toda uma gama de oportunidades ocupacionais em seus diferentes níveis (federal, estadual ou municipal) seja nas empresas públicas seja na administração direta. O magistério, as funções administrativas e os serviços sociais, com horários geralmente flexíveis, oferecendo muitas vezes a possibilidade de acumulação de cargos, constituíram importantes fontes de trabalho remunerado para as mulheres pertencentes às classes médias.

Neste período, as mulheres também já constituíam a metade da população estudantil do ensino médio apta a ingressar nas universidades (VAITSMAN, Jeni, 1994). As estudantes ainda concentravam־se nas áreas de enfermagem, letras e educação, mas aos poucos a participação universitária ia se equiparando à masculina.

Em sociedades que se modernizaram rapidamente, como a brasileira, a formação, cristalização e o armazenamento de identidades, que se sucedem velozmente, dariam ao tempo biográfico uma importância mais crucial do que teria em sociedades que mudam mais lentamente. Nesse processo, o arcaico desapareceria apenas aparentemente, continuando presente de modo invisível, mais ou menos inconsciente, mas opondo-se de forma eficaz ao moderno, que seria "o núcleo daquilo que desejaríamos ser" (ROLNIK, Suely, 1989, p. 77-101). Este tipo de eu multifacetado, em que "as diferentes identidades se distinguem no tempo, além de se distinguirem sincronicamente”, seria uma característica das sociedades modernas. 
A modernização, portanto, obriga as pessoas a passarem por um “processo galopante de desterritorialização (ROLNIK, Suely, 1989, p. 77-101). A consequência disso, é que elas se dão conta de que sua subjetividade é mutável. Com a industrialização da cultura, há uma fartura de matéria de expressão como nunca se conheceu mas também uma automatização da linguagem. E este processo resulta numa saturação de sentido que funciona como num processo inflacionário: "é uma verdadeira falência da credibilidade de todas as espécies de subjetividade, um curto circuito generalizado”.

Nesse contexto, aparece um "espaço de iniciação ao exercício do pensamento como busca da verdade (...) franqueia-se ao pensamento o acesso ao corpo vibrátil e à micropolítica das desterritorializações e das simulações que só esse corpo capta”. Esta é a contribuição mais importante de Freud, segundo Rolnik: "ter introduzido no ocidente moderno uma prática de iniciação ao pensamento assim exercido". E por isso existe "uma mistura nebulosa de potência e fragilidade no ar". A desterritoialização exacerbada em nada garante que se efetuem mudanças significativas; ao contrário, a intenção que predomina é a de "se fazer reconhecer no sistema de hierarquização de sentidos e valores e, com isso, realimentá-lo”. Mas também existe o segundo movimento - o das intensidades e dos investimentos do desejo. As pessoas tendem a confundi-lo por ser invisível com o oculto.

Nesse trabalho de Rolnik, foi observada a importância dos aspectos psicológicos no mundo moderno e a sua relação com a mídia. Entre nós e o mundo estão os meios tecnológicos de comunicação e de simulação. Eles não nos informam sobre o mundo; eles o refazem à sua maneira, transformandoo num espetáculo. Não há pensamento, nem mundo sem algum tipo de representação. Daí a célebre frase de Chartier: “As próprias representações do mundo social são os componentes da realidade social" (CHARTIER, Roger, 1990, p.9). Nesse sentido, cada momento histórico possui o seu dizível e não dizível. Eles são frutos de processos sociais e históricos que buscam instituir e redefinir os espaços de significação. 
Todos os autores que trabalharam com esta problemática estabeleceram relações entre o desenvolvimento de formas de subjetividade e o modo como a sociedade brasileira foi se transformando a partir das últimas décadas. O desenvolvimento de uma sociedade de consumo excludente, onde se acelera a fragmentação social e pessoal e expande uma nova classe média que assimila as ideologias individualistas, constitui a referência macrohistórica para a compreensão dos problemas das leitoras que escreviam cartas às revistas analisadas, da construção de uma nova identidade e do modo como passaram a administrar suas relações interpessoais e de família.

\section{Fontes e Metodologia}

Dezessete publicações compunham na época o Grupo Feminino da Abril, Cláudia, publicada desde 1961, com uma tiragem de 478.379 exemplares mensais e 274 páginas, destinava-se a um público A/B (classes média alta e média). Iniciou em 1961 uma nova fase de imprensa para mulheres: "revistas falando do cotidiano e dos assuntos femininos" (MORAES, Maria Lygia Quartim de, 1981), tendo em vista uma mulher dinâmica, com artigos sobre comportamento tratados de uma forma jornalística. Segundo a redação, esta revista foi feita para a dona-de-casa com uns passos à frente, evidenciando "novas tendências". $\mathrm{Na}$ primeira página vem um pequeno editorial assinado pelo editor-chefe e depois as seções, que se subdividem em O mundo de Cláudia; Moda; Beleza, Decoração, Cozinha e Variedades. Com o artigo, "A arte de ser mulher" a revista faz discussões sobre novos comportamentos. "Amar melhor" também é uma seção dedicada às cartas, juntamente com a "Cláudia responde”.

Nova, publicada em 1973 para um público A/B teve, desde o início, teve o objetivo de conversar com a leitora "de um jeito completamente novo, enfrentando os tabus com bom gosto e com a maior objetividade possível", de acordo com sua redatora, Fátima Ali (Revista Nova n. 23, de agosto de 1975). Com uma tiragem mensal de 290.747 exemplares, 146 páginas, correspondia à Cosmopolitan norte-americana, trazendo uma concepção de mulhermoderna, solteira, sexualmente ativa e independente. Esta mulher gosta de 
desafios, de se conhecer melhor e preocupa-se com o corpo (dietas) e a beleza está ligada à saúde e ao bem-estar. Luta pelos seus direitos e trabalho. Entre as matérias fixas, "Nova na redação" abre a revista, seguida de: "Nova recebe sua carta"; Nova ouve os discos"; Nova lê os livros", "Horóscopo"; "Nova vai ao cinema"; "cuida da saúde"; "Nova e o analista"; Nova conta tudo"; "Moda"; "Culinária"; "Dicas para maquiagem"; "Conto" e uma média de 14 artigos mensais, trazendo questões sexual-afetivas. Os artigos geralmente vêm responder aos problemas de leitoras que escrevem pedindo ajuda. E na maioria foram escritos por estrangeiro(a)s. Os temas políticos aparecem timidamente na década de 1980.

Precedidas por estudos de viabilidade comercial, essas publicações, além de serem previstas para um público particular, foram elaboradas para se tornarem uma rotina na vida do leitor, aberta às possibilidades que surgiram com a rápida urbanização do País. A sofisticação da vida nas grandes cidades exigiu a diversificação dos produtos que lançaram edições especiais independentes, como : "Casa de Cláudia".

Frente à dona-de-casa, representada pela mulher Cláudia, a leitora de Nova é uma mulher que está em constante conflito com os valores estabelecidos e busca novos padrões de comportamento. Nova é destinada à mulher que luta contra seus próprios conceitos psicológicos e morais, embutidos por uma educação tradicional.

Apesar das revistas se destinarem a públicos diferentes, com linguagens e interesses particulares, foi possível agrupar seus artigos em temas especiais - "Nova Mulher"; Sexo"; Conflitos Conjugais"; "Problemas Psicológicos"; "Consultas ao Analista”, objetivando qualificar a problemática e organizar a documentação. Dois núcleos temáticos foram percebidos de acordo com o contexto histórico.

Os temas mais debatidos, entre 1970/1980, eram ligados à auto-estima e auto-afirmação, condições que levaram as mulheres a amadurecerem e a buscarem espaço nas relações de trabalho, além de uma maior abertura nos relacionamentos conjugais. Já de 1980/1990 os novos valores ético-morais 
para o sexo, o redimensionamento da relação homem/mulher e as dificuldades encontradas no mercado de trabalho, impostas pela economia, ocuparam as principais páginas destas revistas.

Veiculadas mais intensamente pela expansão do mercado, suas produções culturais interagiam-se, abrindo possibilidades. Nesse contexto, existiu uma circularidade muito grande entre o público e os editores. Assim como estes, na época, captavam, reproduziam, exploravam, enfim, "fiscalizavam" representações que perpassavam o cotidiano, essencialmente elementos de uma experiência social vivida, por outro lado, o seu público, escrevia as suas ideias e sentimentos para essas revistas, opondo-se às mensagens passadas, ou assumindo o papel que elas lhes apresentavam. Portanto, estabelecia-se uma troca, uma cumplicidade, uma certa sintonia com o(a) autor(a) singularizado na sua mensagem.

Todavia, cabe lembrar que a construção das relações e perfis de comportamento de gênero na dinâmica de transformação urbana se fez através da tecedura de uma trama estando presentes as relações multifacetadas, constituindo-se um processo dinâmico em que os perfis de comportamento de gênero se faziam, desfaziam e refaziam por diferenciação e também por integração (Matos, Maria Izilda S., 1996).

Nesta discussão a categoria de análise gênero amplia o próprio discurso historiográfico influenciando todo o estudo recente sobre as subjetividades. Para Joan Scott, o importante não é refletir ou implementar diferenças físicas entre homens e mulheres, mas estabelecer significações para diferenças corpóreas. Esta perspectiva desmonta conceitualizações que fixam e enquadram os indivíduos e as representações (SCOTT, J., 1986). E enquanto produto cultural, os pós-estruturalistas radicalizarão sua crítica à noção de identidade, estendendo-a para o próprio indivíduo. As diferenças entre os sexos constituem um aspecto primário da organização social e estas diferenças são fundamentalmente culturais. Assim, o gênero é uma forma primeira de significar as relações de poder. Para esta discussão, Foucault continua sendo uma referência muito importante pois pensa "o sujeito como 
efeito, como subjetivação resultante das práticas discursivas que o codificam e de tecnologias disciplinarizantes que o esquadrinham e normatizam" (FOUCAULT, 1982, p. 244). Esta perspectiva reforça que as diferenças sexuais são construções culturais. Enfim, a análise genealógica, na perspectiva deste trabalho, busca mapear os movimentos de sentido que ocorrem a respeito das subjetividades.

\section{Crescimento interior}

As revistas femininas, ao mesmo tempo que veiculavam o que era considerado próprio do "mundo feminino" e as representações das relações homem-mulher, também pretendiam ser formadoras de opiniões, gostos, padrões de consumo e de conduta. Entretanto, de acordo com o seu discurso psicológico, podia- se libertar de tudo o que foi aprendido e tomar consciência da realidade. As pessoas se viam, dentro desta ótica, como sujeitos de suas vidas. Essa foi a grande diferença dos discursos da Cláudia de 1970-1990. Antes ela participava mais explicitamente do processo de reprodução da mentalidade na formação de suas leitoras, procurando discipliná-las de acordo com a ordem socialmente aceita. Os limites da masculinidade e da feminilidade eram reforçados. Já a Revista Nova incorporou a nova linguagem desde a sua primeira edição em 1973.

Agora podia-se dizer que a moral que procurava definir as distinções de gênero era menos rígida que nas décadas anteriores. A assimetria entre os papéis já se tornava menos evidente, partindo para novas práticas e discursividades. A introdução dos conceitos psicológicos no cotidiano das mulheres de classe média afetou as suas relações com elas mesmas e com suas famílias. O indivíduo é assumido como entidade básica. E de acordo com este ideário a "consciência de si" é que passou a ter um caráter formador, pedagógico e educativo por parte da mídia - no sentido foucaultiano de "constituição de sujeitos" ou, "processos de subjetivação".

O processo de crescimento interior, de acordo com a Revista Nova, era vivido por meio das perdas que a vida impõe. E o equilíbrio se estabelecia na 
medida em que essas perdas eram corretamente elaboradas, segundo Marina Colasanti, em seu artigo "Você mulher, você criança"(Revista Nova, set.1980).

Ainda de acordo com a autora, esse processo não permite agarrar-se ao passado, o que impediria o avanço pleno e o amadurecimento. Mas o crescimento é demorado, pontuado por várias etapas, que têm de ser ultrapassadas. Saber que existem conflitos conscientes e inconscientes e administrá-los é o primeiro passo para este empreendimento.

Em seu artigo "Indecisão" para a Revista Nova de dez. 1973, Nora Johnson diz que quando uma escolha por mais insignificante que seja é muito difícil de se fazer, pode ser sinal de conflito bem sério por baixo da confusão superficial. É claro que nessa situação é possível optar por não decidir nada. Segundo a autora, pode-se livrar de tudo isso parando de tentar adivinhar o futuro e decidir por aquilo que se considerar mais certo naquele instante. Mas os conflitos não são sempre internos, eles ocorrem em relação às outras pessoas, pois, aceitar o fato de que cada um precisa ter o próprio espaço parece tão óbvio e simples - e é extremamente complicado. Tem-se um espaço em comum e cada um tem uma vida, cada um é uma pessoa.

Estes textos foram escritos para ajudar a leitora a auto-analisar-se e a identificar-se no mundo em que está - a viver melhor neste mundo e a exercer sua feminilidade, para isso apresentam modelos psicológicos de crescimento emocional e de felicidade. O discurso da Nova tende a ser homogêneo e unilateral. Nesse período, Cláudia conta com os artigos de Carmen da Silva, “A arte de ser Mulher", que de certa forma seguem esta linha de raciocínio.

\section{Não viver para agradar o outro}

Roberto J. Ringer, com o seu artigo "Descobrindo a mulher segura que há em Você” (Revista Nova, out. 1974) reafirma que para não se sentir inseguro(a) todo(a)s devem aprender a não ser submissos, mostrando que podem tomar decisões sozinho(a)s.

Cíntia Pinheiro, em "A armadilha da submissão" (Revista Nova, dez. 1974), também faz a mesma análise. A “independência”, especialmente a 
financeira é decantada na maioria dos artigos. Para discutir este assunto "Ser independente é a glória”, de Neide Ricosti (Revista Nova, abr. 1974, e "Independência que bonita que é", de Marina Colasanti, também para a Revista Nova, jun.1979, reforçam a condição da independência para realizarse no trabalho e afetivamente. É um processo de dentro para fora, segundo os autores, levando a uma vida sem fantasias. Observa-se que a busca da "realização pessoal", fórmula ambígua que pressupõe conciliar o trabalho com a condição de esposa sedutora, atraente, e de mãe disponível e afetuosa, reforça o individualismo, ao associar esta realização a atividades exclusivas do sujeito.

Carmen da Silva (Revista Cláudia, maio, 1979) num artigo intitulado "Maternidade não é uma obrigação é escolha", coloca que o direito de escolher entre ter ou não filhos sempre foi manipulado por outras mãos: as mulheres tendem a fazer o que a sociedade quer e não o que o seu íntimo determina. Ser mãe envolve a personalidade total, a consciência e o inconsciente, o instinto e a razão, as emoções e o corpo - é um projeto pessoal de existência, logo, a opção deve ser consciente, compartilhada ou não.

A redefinição da maternidade foi colocada como um dos aspectos mais importantes para a mulher neste momento. Ela agora é proposta apenas como um dos aspectos na vida da mulher moderna. E Anna Carolina Lo Bianco, sem seu trabalho, "A psicologização do feto" trabalha essa nova maternidade como uma nova experiência materna.

Ainda, de acordo com estas concepções, o reconhecimento dos sentimentos é essencial para se chegar a uma verdadeira autenticidade, tanto em relação a nós mesmos quanto aos demais.

\section{Reconhecer as próprias emoções}

Em um artigo "Agressividade um mal que nos faz bem", Marina Santana (Revista Nova, ago.1979) diz que todo(a)s temem seus sentimentos, mas quando aprendem a conhecê-los e usá-los para a própria felicidade sentem-se mais completos. Socialmente, a única situação na qual a 
agressividade feminina era aceita sem restrições seria quando envolvia a defesa dos filhos. Mas a raiva também pode deflagrar atos de coragem nas mulheres, segundo Jane Clapperton, (Revista Nova, fev. 1980).

Segundo essas autoras, a agressividade é um impulso tão bom quanto a afetividade. Pode-se construir agressivamente, pode-se matar afetivamente. Todos os instintos - o amor, a agressividade, o medo e o sexo - são fundamentais para a sobrevivência. É com eles que se expressam os impulsos internos. A pessoa agressiva costuma ser mais criativa, curiosa, deseja saber como e por que as coisas são propostas. Em "solte suas feras", Marina Colasanti para a Revista Nova, abril, 1980, nos diz que "a raiva, o medo, a insegurança, são feras que não devoram, mas que pode nos melhorar, complementando o amor".

\section{Auto-estima: você é a sua melhor amiga}

Em "o grande amor de sua vida: você", Richard C. Robertiello, num artigo para a Revista Nova, out, 1978, afirma que precisa-se valorizar a si mesmo para dar valor aos outros. Amar a si mesmo é sempre um ponto de partida para inspirar amor.

Geralmente o perfeccionista é criado com alto nível de expectativa, acabando tendo um alto nível de aspiração pessoal. Dessa forma, nunca se consegue atingir seu objetivo e por isso sente-se inferior, condenado a uma grande insatisfação. Ninguém gosta de ser criticado, mas uma crítica construtiva pode ajudá-lo (a) a enfrentar o seu lado não muito bom, segundo Dr. George Weinberg, para a Revista Nova, jan. 1979.

Nesta perspectiva, Marina Colasanti discute em seu artigo "A eterna primeira da classe"(Revista Nova, abr. 1977), que ser eficiente, perfeccionista, adorar desafios, fazer tudo melhor que o(a)s outro(a)s tem um lado bom, que é o do resultado, a segurança que se transmite, a certeza quanto à competência ou à tranquilidade com que a família sabe que pode contar, porém, pode dificultar muito a vida. Aprender a conviver com o lado menos glorioso, admirável e deixar que este lado seja visto, é um exercício de 
coragem. E esta é a única tarefa que, embora bem acabada, não dará um troféu de primeira da classe, mas uma sensação de equilíbrio e bem-estar consigo mesmo(a).

Da mesma forma, se não conseguir descobrir nada de positivo, geralmente se está enganado(a). Thereza Forattini, no seu artigo, "Então você se acha insignificante", ressalta o papel dos pais, avós, ambiente, enfim, relações infantis neste processo.

Algumas pessoas conseguem se reabilitar diante de si mesmas e do mundo, sem o auxílio de um psicanalista, mas, de acordo com estes autores é muito difícil por isso estes temas, acompanhados do discurso científico, recebem um peso especial neste momento.

A universalização do saber psicológico teve um papel e hoje ainda continua a cumprir uma missão de apoio nas crises de homem contemporâneo. Neste período de difusão das psicologias, a psicoterapia chegou a ser definida como "um tratamento médico da alma". Portanto, a grande divulgação das teorias psicológicas deu um poder especial aos especialistas que passaram a ocupar um lugar de destaque em nossa sociedade determinando novas formas de sociabilidade, especialmente na família e em relação à condução moral das pessoas.

Todos estes aspectos foram apresentados nesta pesquisa respaldados por um intenso trabalho documental e analítico. $\mathrm{O}$ esforço do estudioso do discurso está em interrogar a linguagem por ela mesma, sem querer buscar referentes nem fazer interpretações reveladoras de verdades. Trata-se de ficar nos espaços brancos, multiplicando as coisas ditas a partir delas mesmas. A ideia é operar sobre documentos, extrair enunciados, colocando־os em relação uns com os outros respondendo à questão: por que isso é dito aqui, deste modo e nesta situação, e não em outro tempo e lugar e de forma diferente?

Desta forma, pretendi evidenciar como a mídia vem produzindo saberes especializados, no caso, saberes pertinentes ao mundo das mulheres e dos 
homens de classe média, colocando-se numa função social que poderíamos chamar de "pedagógica". Faircloug estuda esta relação entre linguagem e sociedade, buscando compreender a linguagem como prática social, portanto, inserida em contextos específicos de relações sociais formuladas historicamente por meio de conflitos e lutas de poder (FAIRCLOUGH, Norman, 1990). Fazendo a articulação com a pesquisa posso dizer que na minha análise empírica busquei nelas este discurso ou este imaginário que é o ponto de encontro entre a linguagem e a história.

Os conceitos de verdade e saber aqui utilizados estão diretamente relacionados a outros, como os de sujeito, poder e discurso - todos compreendidos dentro da perspectiva de Michel Foucault e das teorias feministas pós-modernistas. $\mathrm{Na}$ esteira dos estudos que se empenham em identificar e articular os diferentes cruzamentos entre sociedade e cultura, este trabalho ocupa-se com a compreensão de um dos aspectos básicos que constituem a cultura de nossos tempos: a ação eficaz e profunda dos meios de comunicação na vida cotidiana.

\section{Referências}

\section{Fontes Consultadas:}

Revista Nova. São Paulo: Ed. Abril.

. Ano 1, número 03. Dezembro, 1973.

. Ano 2, número 05, Fevereiro, 1974.

. Ano 2, número 07, Abril, 1974.

. Ano 2, número 12, Setembro, 1974.

. Ano 2, número 13, Outubro, 1974.

. Ano 2, número 15, Dezembro, 1974.

. Ano 3, número 20, Maio, 1975. 
. Ano 3, número 23, Agosto, 1975.

. Ano 3, número 24, Setembro, 1975.

. Ano 3, número 25, Outubro, 1975.

- Ano 3, número 26, Novembro, 1975.

. Ano 4, número 32, Maio, 1976.

. Ano 5, número 40, Janeiro, 1977.

. Ano 5, número 41, Fevereiro, 1977.

. Ano 5, número 43, Abril, 1977.

. Ano 6, número 57, Junho, 1978.

. Ano 6, número 61, Outubro, 1978.

. Ano 7, número 64, Janeiro, 1979.

. Ano 7, número 69, Junho, 1979.

. Ano 7, número 71, Agosto, 1979.

. Ano 8, número 79, Abril, 1980.

. Ano 8, número 84, Setembro, 1980.

Revista Cláudia. São Paulo: Ed. Abril:

. Ano 13, número 156, Setembro, 1974.

. Ano 14, número 163, Abril, 1975.

. Ano 14, número 178, Agosto, 1975.

. Ano 14, número 179, Setembro, 1975.

. Ano 15, número 184, Março, 1976.

. Ano 18, número 194, Janeiro, 1977.

. Ano 17, número 207, Dezembro, 1978. 
. Ano 18, número 212, Maio, 1979.

. Ano 18, número 213, Junho, 1979.

. Ano 19, número 228, Setembro, 1980.

. Ano 19, número 229, Outubro, 1980.

\section{Bibliografia}

ALVAREZ, Sônia. Politizando as relações de gênero e engendrando a democracia. In: Democratizando o Brasil. Alfred Stepan (Org.). Trad. de Ana Luíza Pinheiro. Rio de Janeiro: Paz e Terra, 1988.

ALVES e BARSTED. Permanência ou mudança: a legislação sobre a família no Brasil. In: RIBEIRO, I. (Org.) Família e valores: sociedade brasileira contemporânea. São Paulo: Loyola, 1987.

BUITONI, Dulcília S. Mulher de papel: a representação da mulher na imprensa feminina brasileira. São Paulo: FFLCH - USP, 1980.

BUTLER, J. Gender trouble. Feminism and the subversion of identity. New York: Routledge, 1990

BIRMAN, Joel. Cartografias do feminino. São Paulo: Ed. 34, 1999.

CANO, Wilson. Transformações da economia e repercussões no mercado de trabalho: roteiro para uma investigação histórica (1920-1986). In: Anais do V encontro nacional de estudos populacionais ABEP. v.2. Águas de S. Pedro, 1986.

CHARTIER, Roger. A Nova História Cultural. Trad. Maria Manuela Galhardo. Lisboa: Difel, 1990.

FAIRCLOUGH, Norman. Language and power. London, Longman, 1990.

FIGUEIRA, S. (Org.). Freud e a difusão da Psicanálise. Porto Alegre: Artes Médicas, 1994. 
FLAX, Jane. Pós-modernismo e as relações de gênero na teoria feminista. In: Pós-modernismo e política. Rio de Janeiro: Rocco, 1991, p. 217-500.

FOUCAULT, M. Microfísica do poder, $3^{\mathrm{a}}$. Ed. Rio de Janeiro: Graal, 1982.

FOUCAULT, M. História da sexualidade 1: a vontade de saber. Rio de Janeiro: Graal, 1990.

GOFFMAN, Erving. A representação do eu na vida cotidiana. Petrópolis: Vozes, 1975.

HOBSBAWM, Eric. Era dos extremos: o breve século XX (1914-1991). São Paulo: Conpanhia das Letras, 1995.

LAURETIS, T. A. Tecnologia do gênero. In: HOLANDA, H. B. (Org.) Tendências e impasses. O feminismo como crítica da cultura. Rio de Janeiro: Rocco, 1994.

MACRAE, Edward. A construção da igualdade: identidade sexual e política no Brasil da abertura. Campinas: UNICAMP, 1990.

MATOS, Maria Izilda S. de. Melodia e sintonia em Lupicínio Rodrigues: o feminino, o masculino e suas relações/ Maria Izilda S. de Matos e Fernando A. Faria. Rio de Janeiro: Bertrand Bradil, 1996.

MONCLAR, Valverde (Org.) As formas de sentido. Estudos em estética da comunicação. Rio de Janeiro: DP\&A, 2003.

MORAES, Maria Lygia Quartim de. Família e Feminismo: reflexões sobre papéis femininos na imprensa para mulheres. São Paulo: FFLCH- USP, 1981. PASTORE, José. Desigualdade e mobilidade social no Brasil. São Paulo: T. A. Queiroz, 1979.

RAGO, Margareth. A categoria gênero no Pós-Modernismo. IFCH:UNICAMP, 1996.

ROLNIK, Suely, Cartografia sentimental: transformações contemporâneas do desejo. São Paulo: Estação Liberdade, 1989. 
SCOTT, Joan W. Gender: a useful category of historical analysis. In: The american historical review v. 91, n. 5, dez., 1986.

SCOTT, Joan W. Gender and the politics of history. New York, Columbia University Press, 1988. (a).

SCOTT, Joan W. Deconstructing equality-versus-difference or the uses of poststructuralist theory for feminism. In: Feminist studies 14. N. 1, spring 1988 (b).

SILVA, Carmen da. A arte de ser mulher. Rio de Janeiro: Civilização Brasileira, 1966.

SKIDMORE, Thomas. Brasil. de Castelo a Tancredo. Trad. de Mário Salviano Silva. Rio de Janeiro: Paz e Terra, 1988.

STEPAN, Alfred. Democratizando o Brasil. Rio de Janeiro: Paz e Terra, 1989.

VAITSMAN, Jeni. O Contexto Brasileiro. In: Flexíveis e plurais: identidade, casamento e família em circunstâncias pós-modernas. Rio de Janeiro.: Rocco, 1994.

Recebido em maio de 2019. Aprovado em julho de 2019. 